\title{
O ESTADO DA ARTE DOS ESTUDOS SOBRE LEGENDAGEM E ENSINO-APRENDIZAGEM DE LÍNGUAS ESTRANGEIRAS NAS ÚLTIMAS DÉCADAS
}

\section{THE STATE OF THE ART OF STUDIES ON SUBTITLING AND FOREIGN LANGUAGE TEACHING AND LEARNING IN THE LAST DECADES}

\author{
Bill Bob Adonis Arinos Lima e Sousa ${ }^{1}$, Vládia Maria Cabral Borges ${ }^{2}$
}

\begin{abstract}
This paper is a bibliographical review of the studies on the task of producing film subtitles, subtitling, for foreign language (FL) teaching and learning. In order to collect data, studies in the following database platforms were researched: (i) Portal de Periódicos CAPES/MEC, (ii) Biblioteca Digital Brasileira de Teses e Dissertações (BDTD), (iii) Google Scholar and (iv) Google.com.br. After applying the criteria for selecting the papers, 20 research studies resulted. The analysis of these papers indicates that there are many benefits of didactic subtitling, including the improvement of FL language skills and the development of intercultural awareness.
\end{abstract}

KEYWORDS: the state of the art; subtitling; foreign language learning

RESUMO: O presente artigo é uma revisão bibliográfica dos estudos que tratam do uso da tarefa de produção de legendas fílmicas, legendagem, para o ensino e aprendizagem de línguas estrangeiras (LE). Para coleta desses trabalhos, consultamos o Portal de Periódicos CAPES/MEC, a Biblioteca Digital Brasileira de Teses e Dissertações (BDTD), o Google Acadêmico e o Google.com.br. Após aplicação dos critérios de seleção, obtivemos 20 pesquisas, cujos resultados indicam diversos benefícios da legendagem didática, como o aprimoramento de habilidades linguísticas em LE e a formação de uma consciência intercultural.

PALAVRAS-CHAVE: estado da arte; legendagem; aprendizagem de língua estrangeira

\section{Introdução}

Este trabalho tem como objetivo principal apresentar uma revisão bibliográfica dos estudos que usam a atividade de legendar, produção de legendas fílmicas, no ensino e

\footnotetext{
${ }^{1}$ Doutorando em Linguística na Universidade Federal do Ceará. Professor do Instituto Federal de Educação, Ciência e Tecnologia do Ceará - IFCE - Campus Baturité

2 Ph.D. em Educação - Ensino de Inglês como Segunda Língua pela Universidade de Rhode Island, EUA. Professora do Departamento de Estudos da Língua Inglesa, suas Literaturas e Tradução da Universidade Federal do Ceará.
} 
aprendizagem de línguas estrangeiras ${ }^{3}$ (LE). Os estudos analisados aqui, em sua grande maioria, versam sobre o ensino de língua inglesa (LI), apesar de, na metodologia desta pesquisa, buscarmos trabalhos que pudessem contemplar qualquer LE.

É vasta a literatura que investiga a influência do acesso a materiais audiovisuais legendados no ensino e aprendizagem de LE (DANAN 1992; 2004; NEVES 2004; CHAGAS 2005; GOMES 2006; 2016; ARAÚJO 2008; PAVESI; PEREGO, 2008; OLIVEIRA FILHO 2008; DÍAZ CINTAS 2008; DÍAZ CINTAS; CRUZ, 2008; CAIMI 2009; FAZILATFAR, GHORBANI E SAMAVARCHI 2011; MATIELO; COLLET; D'ELY, 2013; HSU et al. 2013; MATIELO; D'ELY; BARRETA, 2015). Nesses estudos, investiga-se como os filmes/vídeos legendados podem ser usados para promover o desenvolvimento das diversas habilidades linguístico-comunicativas nas LE. No entanto, nessa área de pesquisa, pareceu-nos haver uma carência de trabalhos que investiguem como os estudantes podem aprender uma LE legendando, construindo objetos reais (SOKOLI 2006; ZANÓN 2010; LERTOLA 2012; BORGHETTI E LERTOLA 2014) e não apenas sendo submetidos a vídeos com legendas.

Com o intuito de acessar o "estado da arte" nesse âmbito, fizemos uma busca sistematizada por trabalhos, utilizando quatro bibliotecas digitais: o Portal de Periódicos CAPES/MEC, a Biblioteca Digital Brasileira de Teses e Dissertações (BDTD), o Google Acadêmico e o Google.com.br. Para cada biblioteca, padronizou-se a busca por meio das ferramentas disponíveis nos mecanismos de pesquisa. Em todos eles, marcou-se como limite temporal os últimos $20 \operatorname{anos}^{4}$. Os trabalhos coletados foram aqueles (disponíveis gratuitamente) que contemplavam em seus títulos ou resumos as palavras-chave e/ou metodologia que satisfizessem o tema procurado.

As palavras-chave usadas foram, em português, "legendagem" combinada com "aprendizagem língua", "ferramenta pedagógica", “desenvolvimento proficiência", "desenvolvimento habilidades língua", "atividade aprendizagem língua"; em inglês, "subtitling" combinada com "language learning", "pedagogical tool”, "language proficiency development", "language skill development", “activity language learning". Como já era previsto, pelo uso do termo "legendagem" como palavra-chave, em todas as buscas, houve repetições de resultados em buscas ulteriores. Nesses casos, registramos essas repetições, mas

\footnotetext{
${ }^{3}$ Usa-se, aqui, a expressão "língua estrangeira" (LE) como um hiperônimo, ou seja, sempre que se estiver falando de línguas que não são nativas, abarcando assim, também, a noção de segunda língua (L2) e línguas adicionais.

${ }^{4}$ A coleta de dados foi feita em 2018.
} 
contabilizamos apenas os resultados novos, eliminando os demais. Com essa abordagem bilíngue, objetivou-se coletar um maior número de trabalhos.

Contudo, não seria factível, dados os propósitos deste estudo, verificar todos os resultados gerados. No Google, por exemplo, para cada busca, o mecanismo gera centenas de resultados, os quais se distanciam das palavras-chave a medida em que se avança o número de páginas no navegador web. Por isso, neste levantamento bibliográfico, optamos por analisar apenas os 50 primeiros resultados.

A metodologia para a coleta de trabalhos se fez em três etapas. Na primeira, coletamos os trabalhos nos quais o título apresentava nossas palavras-chave sugerindo pertinência ao nosso estudo. Na segunda etapa, lemos os resumos desses trabalhos, verificando se estes corroboravam essa pertinência. Por último, fizemos a leitura dos artigos, dissertações e teses, em sua integridade, a fim de apropriar-nos de seus conteúdos. Seguem a descrição dos demais procedimentos utilizados para a seleção de trabalhos e os resultados obtidos em cada biblioteca. No tratamento e análise dos dados, descrevem-se a agenda da pesquisa da área, os projetos com tarefas de legendagem, os benefícios da legendagem didática e as orientações para implementação de tarefas de legendagem em sala de aula de LE.

\section{Tarefas de legendagem nas bibliotecas digitais}

Os acervos digitais vêm facilitando bastante o trabalho dos pesquisadores. Hoje, podemos consultar livros, artigos, dissertações e teses em poucos cliques. Todavia, são necessários conhecimentos e habilidades para a obtenção de resultados satisfatórios nesses ambientes virtuais. Abaixo estão os procedimentos utilizados para a coleta do corpus deste estudo.

No Portal de Periódicos CAPES, por meio do ACESSO CAFE, selecionou-se a opção "Buscar assunto", a qual consulta simultaneamente as várias coleções do Portal. Em "Personalize your results", marcou-se a opção "Artes e Humanidades" que inclui filosofia, religião, história, arqueologia, língua e literatura. Foi selecionada também a caixa "Prefer newer material". Algumas das pesquisas escolhidas não puderam ser acessadas diretamente do Portal de Periódicos. Nesses casos, clicamos na aba "Detalhes", copiamos a fonte da publicação e fizemos uma pesquisa usando o mecanismo Google. Algo que facilita bastante a busca no Portal são as marcações das palavras-chave em amarelo. Isso poupa bastante esforço e torna a busca mais intuitiva. Vejamos, nas Figuras 1 e 2, o resumo da primeira parte da coleta. 


\begin{tabular}{lccc}
\hline Palavras-chave (em LP): legendagem + & Encontrados & Selecionados/Mantidos \\
\hline aprendizagem língua & 01 & 00 \\
ferramenta pedagógica & 00 & 00 \\
desenvolvimento proficiência língua & 00 & 00 \\
desenvolvimento habilidades língua & 03 & 00 \\
atividade aprendizagem língua & 00 & 00 \\
Total & $\mathbf{0 4}$ & $\mathbf{0 0}$
\end{tabular}

Total de trabalhos selecionados $=00$

Figura 1 - Trabalhos selecionados no Portal de Periódicos CAPES/MEC 1 LP = língua portuguesa

Fonte: Elaborada pelos autores.

Na Figura 1, observa-se que encontramos quatro trabalhos, porém ao lermos os resumos desses estudos verificamos que eles não constituíam o nosso corpus, já que o nosso interesse se centra em pesquisas que usem o ato de legendar relacionado à aprendizagem de LE. Por esse motivo, esses estudos encontrados não foram mantidos.

\begin{tabular}{lccc}
\hline Palavras-chave (em LI): subtitling + & Encontrados & Selecionados/Mantidos \\
\hline language learning & 07 & 07 \\
pedagogical tool & 04 & 01 \\
language proficiency development & 00 & 00 \\
language skill development & 00 & 00 \\
activity language learning & 02 & 00 \\
Total & $\mathbf{1 3}$ & $\mathbf{0 8}$
\end{tabular}

Total de trabalhos selecionados $=08$

\section{Figura 2 - Trabalhos selecionados no Portal de Periódicos CAPES/MEC 2 $\mathrm{LI}=$ língua inglesa Fonte: Elaborada pelos autores.}

Como foi dito, e podemos verificar na Figura 2, pela repetição da palavra-chave subtitling, encontramos resultados repetidos em buscas ulteriores. Dessa forma, mantivemos apenas os trabalhos novos encontrados, 8 (oito), eliminando os que se repetem, 5 (cinco).

No mecanismo de busca da Biblioteca Digital Brasileira de Teses e Dissertações (BDTD), mantiveram-se selecionados os termos "all fields" e "all terms". Não usamos filtro de 
idioma nem de nível de pós-graduação. O mecanismo, a exemplo do Portal de Periódicos, destaca em amarelo as palavras-chave. Porém, nessa base de dados não encontramos trabalhos que pudessem ser selecionados.

No Google Acadêmico, manteve-se o padrão de busca do mecanismo, "classificar por relevância", e marcou-se a opção pesquisar "em qualquer idioma". As marcações das palavraschave, nos resultados, são apresentadas em negrito nesse mecanismo. Foram selecionados 01 (hum) trabalho, por meio da busca em língua portuguesa (LP) e 15, por meio da busca em língua inglesa (LI).

Ao consultar a biblioteca Google.com.br, além dos parâmetros de pesquisa usados no Google Acadêmico, incluímos como filtro o termo "pdf" nas palavras-chave, com o objetivo de evitarmos resultados muito genéricos. Selecionamos 01 (hum) trabalho, por meio da busca em LP e 03 (três), por meio da busca em LI. Segue o resumo dos trabalhos selecionados nas bibliotecas digitais (Figura 3), os quais totalizaram, preliminarmente, 28 trabalhos.

\begin{tabular}{lcc}
\hline Bibliotecas digitais & Busca em LP & Busca em LI \\
\hline Portal de Periódicos - CAPES/MEC & 00 & 08 \\
BDTD & 00 & 00 \\
Google Acadêmico & 01 & 15 \\
Google.com.br & 01 & 03 \\
Total & $\mathbf{0 2}$ & $\mathbf{2 6}$
\end{tabular}

Total de trabalhos selecionados $=\mathbf{2 8}$

\begin{tabular}{l|c}
\hline Gêneros selecionados & Quantidade \\
\hline Artigos & $\mathbf{2 5}$ \\
Dissertações de mestrado & $\mathbf{0 1}$ \\
Teses de doutorado & $\mathbf{0 2}$ \\
\hline
\end{tabular}

Figura 3 - Número e tipo de trabalhos selecionados nas bibliotecas digitais LP = língua portuguesa; $\mathrm{LI}=$ língua inglesa Fonte: Elaborada pelos autores.

Após uma avaliação, que consistiu em uma leitura completa dos trabalhos, selecionamos aqueles que compuseram o corpus deste estudo. Nessa leitura, buscamos identificar, especificamente, se na metodologia dos trabalhos, em algum momento os estudantes produziam legendas fílmicas com vistas a aprimorar suas habilidades em LE. Assim, dos 28 trabalhos 
selecionados, mantivemos 20 (vinte), 18 (dezoito) artigos e as 02 (duas) teses de doutorado, os quais passamos a discutir agora.

\section{Tarefas de legendagem no ensino-aprendizagem de LE}

Nesta seção, discutimos os 20 trabalhos pertinentes ao tema desta pesquisa. Apesar da escassez de estudos que investiguem o ato de legendar direcionado ao ensino-aprendizagem de LE, encontramos, nos trabalhos investigados, dados bastante positivos sobre o tema. Nesses estudos, fizemos um apanhado das informações sobre a agenda de pesquisa da área, projetos, benefícios da legendagem didática e orientações para implementação de tarefas de legendagem em sala de aula de LE.

\subsection{Agenda de pesquisa}

As pesquisas na área de legendagem e ensino-aprendizagem de línguas vêm crescendo nos últimos anos. Zanón (2010) verificou que as três modalidades de legendas

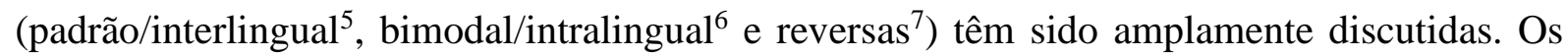
ganhos provenientes do uso desse tipo de material legendado são diversos, seja no desenvolvimento das habilidades escritas e orais, seja no desenvolvimento de uma consciência intercultural, pragmática e metalinguística. O que a autora sublinha, porém, é a carência de estudos que façam uso de softwares de legendagem para realização de atividades de tradução audiovisual (TAV).

Não obstante, Beseghi (2013) nos mostra que alguns autores estudam o processo de legendagem, como Blane, 1996; James, 1998; Díaz Cintas, 2001; Bartrina, 2003; 2009; Bartrina; Espasa, 2005. Porém, nesses estudos, esses autores focam mais nas constrições impostas por essa modalidade de tradução audiovisual (TAV) do que nas possibilidades que a legendagem pode oferecer em sala de aula de LE. Nesse último aspecto, Beseghi vê em Díaz Cintas et al (2008) o limiar para novos estudos que tratem dessa questão. Em consonância, Lertola (2012) destaca o interesse crescente em pesquisas sobre a legendagem, relatando que

\footnotetext{
${ }^{5}$ A legendagem interlingual é aquela em que o áudio original do vídeo/filme se encontra em LE e as legendas são produzidas em língua nativa (língua de chegada).

${ }^{6}$ A legendagem intralingual é aquela em que o áudio original e as legendas se encontram na língua original do vídeo/filme.

${ }^{7}$ Legendagem reversa é aquela em que temos o áudio na língua nativa e as legendas na LE.
} 
isso não se limita à área da tradução profissional, mas também ao reflexo dessa prática na aprendizagem de LE.

Lertola (2013) registra que instituições europeias não apenas reconhecem o potencial do consumo de materiais legendados, mas também da legendagem, produção de legendas fílmicas por aprendizes de línguas, como ferramentas efetivas no processo de ensinoaprendizagem de idiomas. A autora ressalta que, apesar do pequeno volume de estudos em relação à prática de legendagem, esse é um campo de pesquisa que está se desenvolvendo rapidamente, uma vez que os resultados de estudos empíricos trazem dados positivos concernentes ao uso dessa ferramenta no desenvolvimento global da aprendizagem de LE. Borghetti e Lertola (2014) também admitem a vasta literatura sobre legendagem e ensino de línguas existente nos dias atuais. Contudo, as autoras, consoante ao que se lê acima, sinalizam a carência de pesquisas que tratem da produção de legendas como um meio de aprendizagem intercultural.

Por fim, no apanhado dos estudos que investigamos, Marzban e Zamanian (2015) concordam que as pesquisas sobre a produção de legendas fílmicas por aprendizes de LE ainda são restritas, porém os autores sublinham que estudos recentes como os de Williams e Thorne, 2000; Sokoli, 2006; Bravo, 2008; e Talaván, 2010, trazem resultados positivos em relação ao uso da legendagem intralingual e interlingual. Poucos parecem ser, também, os projetos que fomentam tarefas de legendagem.

\subsection{Projetos - ClipFlair e LvS}

Encontramos em nossa busca dois projetos de interesse. O primeiro, ClipFlair, é uma plataforma europeia online de aprendizagem de LE baseada em atividades de dublagem e de legendagem. Trata-se de um projeto financiado pela European Comission que objetiva melhorar a interatividade no trabalho com materiais audiovisuais. Para isso, criou-se uma plataforma onde alunos, professores e produtores de material didático podem interagir. Para criação da plataforma, seus idealizadores fizeram um estudo sobre as pesquisas existentes no campo da TAV, bem como promoveram discussões sobre quais abordagens de ensino de LE seriam usadas, quais habilidades seriam focalizadas e qual seria o público-alvo. Inicialmente, duas plataformas de aprendizagem foram criadas: ClipFlair Studio, com recursos audiovisuais de aprendizagem e ClipFlair Social, um espaço para interação em comunidade (BAÑOS; SOKOLI 2015). 
De acordo com Baños e Sokoli (2015), as plataformas do projeto ClipFlair (de acesso gratuito) foram construídas de forma colaborativa, com feedback contínuo dos usuários. Seus idealizadores categorizaram as atividades desse ambiente de aprendizagem com base em três tipos de respostas de aprendizagem: a repetição, a paráfrase e a reação; o que corresponde respectivamente, à reprodução literal daquilo que é verbalizado nos vídeos, à reprodução livre do texto e à produção de uma nova contribuição comunicativa em resposta à produção audiovisual. Em 2015, o ClipFlair já contava com 350 atividades de revoicing e legendagem, objetivando-se a aprendizagem de mais de 19 línguas. Essas atividades abrangem desde as mais simples, como preencher lacunas, até as mais complexas, como legendar em LE sem acesso a um roteiro/transcrições. O retorno dos usuários foi bastante positivo. Oitenta por cento (80\%) dos aprendizes relataram gostar das atividades e por volta de oitenta por cento (80\%) dos professores e alunos disseram não ter tido problemas com a tecnologia.

O Segundo projeto, LvS (Learning via Subtitling), programa de legendagem, é apresentado por Sokoli (2006), que argumenta que a legendagem enquanto tarefa não pode ser um simples "algo a mais" no ensino de LE, ela deve figurar como a parte central de uma atividade coerente.

Os autores do LvS implementaram um programa que carrega atividades didáticas de legendagem. Com uso desse programa, os estudantes podem criar legendas para cenas de filmes, por exemplo. O LvS também permite que o professor de LE dê um retorno ao aluno fazendo correções e comentários para que este possa refazer sua atividade.

Sokoli (2006) enumera diversos benefícios advindos do uso do LvS no ensino de LE. Suas atividades seguem as propostas de autoaprendizagem, ensino à distância e o formato de centros de autoacesso, como também funcionam na sala de aula de LE. Essas atividades são permeadas de microatividades, tais como resumir partes de monólogos e diálogos, priorizar informações com vistas a atender a critérios de legendagem (constrições de espaço, por exemplo) e integrar estratégias de leitura. A principal limitação do LvS é o fato de o software existir apenas na versão para aprendizagem, o que significa que o professor de LE depende da ajuda dos desenvolvedores do programa para elaboração de novas atividades. A seguir, apresentamos estudos que mostram alguns benefícios do trabalho com legendagem de vídeos.

\subsection{Alguns benefícios da legendagem didática}

O interesse por materiais didáticos audiovisuais não é algo novo; diversas editoras, há bastante tempo, já vêm produzindo esse tipo de material. Já a exploração da TAV não parece 
ser algo amplamente difundido, apesar das diversas vantagens assinaladas por estudiosos da área. Segundo Sokoli (2006), diversos estudos mostram que estudantes de legendagem se beneficiam do trabalho de tradução de vídeos, melhorando sua consciência linguística, o que se reflete em outros cursos e atividades das quais esses estudantes participam. Para Zanón (2006a), os materiais audiovisuais, por seu caráter multimodal (som, imagem, palavras), contribuem na aprendizagem de LE para diversos tipos de aprendizes e a atividade de legendagem em si figura como um elemento capaz de fazer com que um aprendiz de LE seja sujeito ativo do seu próprio processo de aquisição ${ }^{8}$.

No processo de legendagem interlingual, Williams e Thorne (2000) elencam diversas oportunidades de exercício das habilidades linguísticas. Dentre elas, destacamos a interação entre o professor (tutor) e o estudante que podem usar língua-alvo para revisar os trabalhos de TAV feitos em sala de aula/laboratório de idiomas. Nessa etapa, vários aspectos do texto de tradução (TT) são contemplados: sua composição, edição, precisão linguística etc. Isso enseja um ótimo momento de aprendizagem, já que os alunos precisarão justificar suas escolhas tradutórias (WILLIAMS; THORNE, 2000). Consoante à essa perspectiva, Beseghi (2013, p. 396, tradução nossa $\left.{ }^{9}\right)^{10}$ assevera que

Uma abordagem comunicativa de tradução é aquela que vai além do procedimento tradicional de exercício-correção-discussão, recriando uma situação autêntica, em que os estudantes traduzem como se estivessem em um ambiente profissional ou semiprofissional. O professor de tradução pode atuar como facilitador, fornecendo diversas estratégias e orientando o acesso a diferentes tipos de materiais, e qualquer curso de tradução deveria considerar fornecer aos alunos ferramentas para lidar com o maior número de tipos de textos possível.

Além de destacar a importância do uso de materiais autênticos ${ }^{11}$ no ensino de LE, Beseghi (2013) considera, na tarefa de produção de legendas, vantagens como a construção de um objeto que pode ser usado por outros estudantes ou até mesmo publicado na internet. Descendo ao nível linguístico, a autora percebe, nos procedimentos de síntese e de segmentação, aspectos centrais do processo de legendagem para promoção das habilidades de compreensão textual.

\footnotetext{
${ }^{8}$ Cf. Freire (2018).

${ }^{9}$ As traduções contidas neste trabalho são de nossa autoria e servem para fins meramente didáticos.

10 A communicative approach to translation is one that goes beyond the traditional procedure of exercisecorrection-discussion and recreates an authentic situation, where the students translate as if they were in a professional or semi-professional environment. The translation teacher can take the role of facilitator, by providing a series of strategies and by giving access to different kinds of materials, and any translation course should consider giving students the tools to deal with as many types of texts as possible.

${ }^{11}$ Entende-se por "materiais autênticos", nesta pesquisa, aqueles que não foram produzidos, primeiramente, para fins pedagógicos/didáticos.
} 
Em Zanón (2006a), temos a discussão da produção de legendas fílmicas, no ensino de LI, por estudantes da área de negócios. A autora vê nessa modalidade da TAV um meio para fazer com que os alunos “[...] produzam língua em um contexto familiar e motivador [...]”. Com isso, "eles são impelidos a desempenhar um papel ativo em seu processo de aprendizagem, aumentando-se a motivação e a aquisição linguística." (ZANÓN, 2006a, p. 316). ${ }^{12}$ Além disso, ela destaca a importância de o aluno estar construindo um objeto real, legendas para um vídeo, o que torna a atividade mais motivante, ao trazer uma noção de propósito.

Além desses benefícios, a autora destaca que a legendagem ajuda os estudantes a compreenderem a coerência e a coesão interna do material discursivo com o qual estão trabalhando. Portanto, eles se apropriam das características desse gênero textual multimodal, em sua complexidade. "Essa compreensão é bem abrangente, já que ela ajuda os alunos a melhorar sua proficiência leitora, compreensão oral, bem como sua produção escrita e oral.” (ZANÓN, 2006a, p. 338) ${ }^{13}$.

Bravo (2008), por seu turno, mostra que uma das vantagens desse tipo de material é trazer língua autêntica contextualizada, ao contrário de materiais preparados para fins didáticos. A autora sublinha, nesse contexto, a importância de, nos estágios iniciais de aprendizagem, permitir que o aluno use sua língua nativa, mantendo assim (o que Krashen recomenda) o filtro afetivo baixo.

Lertola (2013) considera a legendagem uma tarefa capaz de trazer resultados tangíveis, podendo ser conduzida individualmente ou em duplas, tanto em ambientes presenciais quanto virtuais. O tipo de legendagem usada, segundo a autora, pode melhorar a habilidade de compreensão oral bem como a de leitura, além de promover o conhecimento de elementos culturais da LE.

Entendemos que para além dos ganhos linguísticos, estão os ganhos didáticos que uma tarefa de tradução desse tipo pode oferecer. Primeiro, ela permite que professores e alunos interajam com o objetivo de construírem um objeto concreto que possa ser compartilhado com outras pessoas. Segundo, a tarefa de legendagem é centrada no estudante, ela pode ser conduzida individualmente ou em pequenos grupos, o que promove a autonomia e a cooperação

\footnotetext{
$12[\ldots]$ create language within a very familiar and motivating context $[\ldots]$ forces them to play an active role in their own learning process, so motivation and language acquisition is enhanced.

${ }^{13}$ This understanding is very comprehensive, given that it helps learners enhance future reading and listening comprehension, as well as writing and speaking production practices.
} 
durante o processo de ensino-aprendizagem. Ainda, ela ajuda a desenvolver outras habilidades como aquelas relacionadas à resolução de problemas e ao letramento digital ${ }^{14}$.

Talaván e Rodríguez-Arancón (2014) também compreendem que a atividade de legendagem deve ser exercitada de forma colaborativa; pois, argumentam as autoras seguindo Vigotsky, a aprendizagem é intrinsicamente social. Voltando-se mais diretamente para a TAV, elas vêm na legendagem reversa uma ótima ferramenta para o desenvolvimento da habilidade de produção textual em LE.

Essa atividade pode ajudá-los a aprimorar as habilidades de produção escrita em LE, já que eles têm que ter atenção não apenas à reformulação e condensação, mas também a outros aspectos relevantes como à busca pelo registro e estilo corretos, à correta sequência de ideias e ao uso apropriado de coesão e coerência, bem como às normas ortográficas. (TALAVÁN; RODRÍGUEZ-ARANCÓN, 2014, p. 86) ${ }^{15}$.

McLoughlin e Lertola (2014) advogam a favor do uso da legendagem no ensino de línguas destacando várias vantagens do uso dessa ferramenta, entre elas o desenvolvimento de uma consciência intercultural ${ }^{16}$ e pragmática. Elas relatam que, com avanço tecnológico, cada vez mais a TAV vem ganhando espaço no ensino de LE, mormente na modalidade legendagem. As autoras explicam que com uso desse material o input fornecido ao estudante é composto por quatro tipos de informação: não-verbal visual (imagens), não-verbal sonoro (trilha sonora), verbal escrito (legendas), verbal sonoro (diálogos falados). Ademais, McLoughlin e Lertola (2014) ressaltam que o uso da legendagem extrapola a prática das quatro habilidades linguísticas, promovendo o que Zabalbeascoa, Sokoli e Torres (2012) chamam de letramento audiovisual, o conhecimento das nuances que envolvem a atividade de produzir legendas fílmicas.

No que se refere à aprendizagem intercultural combinada à tarefa de legendagem, Borgetti e Lertola (2014) asseveram que o estudante passa da condição de um leitor regular do texto audiovisual à condição de tradutor. Isto implica na forma como o aluno examina o vídeo, acessando, de forma mais cuidadosa, a cultura fonte e a alvo a fim de produzir um texto compreensível (legendas interlinguais) para um espectador de chegada.

Zanón (2010) corrobora os trabalhos acima sublinhando algumas vantagens desse tipo de tarefa para o ensino de LE, como a funcionalidade e a interatividade de alguns exercícios

\footnotetext{
${ }^{14}$ Cf. Cirugeda e Ruiz (2013).

15 This activity can help them to foster L2 writing skills, since they have to pay attention not only to rephrasing and condensation, but also to other relevant aspects such as the search for the right register and style, the correct sequencing of ideas and the appropriate use of cohesion and coherence, as well as of spelling norms.

${ }^{16}$ Cf. Al-Dabbagh (2017).
} 
que permitem aos estudantes compartilhar seus trabalhos com seus pares ${ }^{17}$, bem como os diversos benefícios que este tipo de atividade traz à aquisição vocabular ${ }^{18}$ e à compreensão textual.

Nesse sentido, Neves (2004), ao abordar a questão da inserção de disciplinas de legendagem nos cursos de formação de tradutores, considera que, apesar de muitos dos estudantes de tradução não estarem interessados em ser legendistas, a partir das aulas de TAV com legendagem eles se beneficiam com desenvolvimento de sua consciência linguística.

Por fim, Versari e Marins (2014), reconhecendo a revolução tecnológica em que vivemos e a geração de jovens nativos digitais que temos em nossas salas de aula, propõem o uso de atividades de legendagem em sala de aula de LI no ensino médio paranaense como um meio de formar alunos mais críticos e promover a motivação para a aprendizagem da LE. As autoras salientam a urgência da implementação de novas tecnologias em sala, ressaltando que estas jamais poderão substituir os professores de LE.

$\mathrm{Na}$ Figura 4, podemos observar os principais benefícios advindos das tarefas de legendagem, de acordo com os estudos acima. Relatamos e discutimos, na seção seguinte, algumas metodologias usadas para execução de tarefas de legendagem.

\footnotetext{
${ }^{17}$ Cf. Vigotsky (2007).

${ }^{18}$ Cf. Lertola (2013) e Al-Dabbagh (2017).
} 


\begin{tabular}{|l|l|}
\hline Benefícios da legendagem didática & Estudos \\
\hline Promoção de uma consciência linguística & Sokoli (2006); Neves (2004) \\
\hline Abordagem centrada no aluno & Zanón (2006a) \\
\hline Interação entre professor e alunos & Williams e Thorne (2000) \\
\hline Interação entre alunos & Zanón (2010) \\
\hline Abordagem comunicativa de tradução & Beseghi (2013) \\
\hline Construção de um objeto real & Beseghi (2013); Zanón (2006a) \\
\hline Promoção das habilidades de compreensão textual & Beseghi (2013); Lertola (2013) \\
\hline Produção de traduções livres & Beseghi (2013) \\
\hline Aquisição vocabular & Beseghi (2013); Lertola (2013) \\
\hline Desenvolvimento da habilidade de produção escrita & Zanón (2006a); Talaván e Rodríguez-Arancón \\
& (2014) \\
\hline Aprimoramento da ortografia & Zanón (2006a) \\
\hline Aperfeiçoamento da habilidade de compreensão oral & Lertola (2013) \\
\hline Formação de uma consciência intercultural & Lertola (2013); McLoughlin e Lertola (2014) \\
\hline Deslocamento da condição de espectador à de tradutor & Borghetti e Lertola (2014) \\
\hline Formação de alunos críticos & Versari e Marins (2014) \\
\hline
\end{tabular}

Figura 4 - Benefícios da legendagem didática para aprendizagem de uma LE Fonte: Elaborada pelos autores.

\subsection{Orientações para o desenho e implementação de tarefas de legendagem}

Os estudos relatados a seguir podem servir como orientação para o desenho e implementação de tarefas de legendagem. Neles, percebemos uma diversidade de metodologias capazes de instruir a construção de tarefas. Passamos a descrever o que vem sendo feito nesse campo de estudo.

Para implementação de tarefas de legendagem, Zanón (2006a) propõe a combinação de programas computacionais, vídeos, legendas e atividades interativas que promovam a integração das quatro habilidades linguísticas. A autora recomenda, ainda, o uso de uma abordagem comunicativa combinada à aprendizagem baseada em tarefa. Em relação aos vídeos a serem legendados, Zanón (2006a) entende como melhor opção as séries televisivas e os sitcoms. Seguindo também uma visão conteudista, ela sugere que os vídeos escolhidos se atrelem àquilo que se pretende trabalhar em sala, como saudações, pedidos etc.

Uma proposta de tarefa da autora se resume à produção de legendas, pelos alunos, para fragmentos audiovisuais por meio de um programa de legendagem. Por ser gratuito e por ter uma interface simples, Zanon (2006a) recomenda o uso do programa subtitle workshop. No que 
se refere ao tipo de legenda a ser produzida, a autora prevê os tipos intralingual, interlingual ou reversas. Estruturalmente a atividade segue as etapas de pré-tarefa, tarefa e pós-tarefa. A autora sublinha, também, que essa atividade pode ser usada como ponto de partida para se estudar tópicos dos programas dos cursos, como pronúncia, podendo ser aplicada na modalidade presencial ou à distância.

Partindo do entendimento de que vídeos autênticos podem ser usados com alunos de LE em qualquer nível de proficiência linguística, Zanón (2006b) orienta que se deve aplicar materiais e atividades adequadas, a fim de monitorar esse uso. Nesse sentido, a autora recomenda que as atividades com vídeos sejam reforçadas por outros exercícios, antes, durante e após sua execução.

A seleção e preparação de material a ser legendado é uma etapa, segundo a autora, de responsabilidade do professor de $\mathrm{LE}^{19}$. Em relação à duração dos vídeos, Zanon sugere o uso de vídeos curtos, de um a seis minutos. Com isso, vários aspectos de ensino de LE podem ser abordados: gramática, funções comunicativas, vocabulário ${ }^{20}$, pronúncia etc. O papel do professor de LE, durante a execução das tarefas de legendagem, é aquele de mediador ${ }^{21}$. Ou nas palavras de Zanón $\left(2006\right.$ b, p. 332) ${ }^{22}$ : “[...] ele precisa agir como um orientador e auxiliar, que os estudantes sabem estar sempre disponível."

Ao discutir a inserção da TAV nos cursos de formação de tradutores, Neves (2004) divide a legendagem de vídeos em quatro etapas. A primeira etapa se refere à investigação do suporte em que o texto é veiculado e a segunda à investigação do roteiro, o qual pode ser valioso ao incorporar transcrições e anotações sobre as produções fílmicas. Mesmo um roteiro ruim pode ser proveitoso em uma aula de legendagem, pois permite reflexão a partir de um trabalho comparativo. A terceira etapa trata-se da tradução propriamente dita. A quarta etapa é a sincronização que pode acontecer em diferentes momentos a depender da metodologia usada pelo tradutor. Trata-se da inserção das legendas no texto fílmico.

Em relação ao tempo investido nessas tarefas, McLoughlin e Lertola (2014) chamam a atenção para a carga-horária de uma atividade de legendagem, a qual requer tempo para um treinamento com um software. Assim, argumentam que esse tipo de atividade não deve ser

\footnotetext{
${ }^{19}$ Como essa é uma atividade laboriosa e como nem todos os professores de LE têm facilidade em lidar com as novas tecnologias, a construção coletiva e o compartilhamento desse tipo de material didático é um bom caminho a ser seguido. Em instituições em que há equipes de professores conteudistas, um bom treinamento pode facilitar a implementação desse tipo de tarefa na rotina pedagógica dos mais diferentes contextos de ensino de LE.

${ }^{20}$ Cf. Bianchi (2015).

${ }^{21}$ Cf. Figueiredo (2019).

${ }^{22}[\ldots]$ he needs to act as a guide and helper, that learners know is always there.
} 
ocasional, mas sistemática, de forma que o tempo inicial investido possa ser melhor aproveitado nas lições seguintes, que se tornarão cada vez mais fluentes à medida que os estudantes se inteirem dos elementos da TAV. As autoras aplicaram essa ferramenta de ensino por meio de uma metodologia constituída de cinco fases: motivação, apresentação da atividade de legendagem; percepção global, apresentação do vídeo em LE a ser traduzido; análise, desconstrução e compreensão do input em LE; síntese, tradução e legendagem do vídeo; reflexão, discussão da atividade de legendagem.

Em Zanón (2010), encontram-se destacados os aspectos a serem definidos previamente às atividades de legendagem, a saber: o software a ser usado (segue a recomendação do subtitle workshop); os tipos de legendas que serão apresentadas aos alunos; os tipos de legendas que eles produzirão; as características dos vídeos, como a duração e o conteúdo, por exemplo; e os tipos de tarefas de aprendizagem.

Seguindo esse roteiro, Zanón sugere uma aula com dois vídeos curtos (algo em torno de um ou dois minutos e que contemplem uma temática afim), um deles a ser legendado; préexibição do vídeo (com legendas intralinguais, bimodal) a ser traduzido com legendas interlinguais; criação de legendas (individualmente ou colaborativamente); exibição do segundo vídeo com legendas intralinguais; discussão oral e proposição de atividades para o último vídeo. A escolha de vídeos com conteúdos semelhantes justifica-se porque, ao legendarem o primeiro vídeo, os alunos poderão lançar mão do que aprenderam com essa atividade para interpretar e resolver questões relacionadas ao segundo vídeo.

Essa divisão das tarefas de legendagem em etapas faz parte da natureza da atividade. Laviosa (2015) descreve uma unidade pedagógica organizada em quatro fases. Na primeira, a autora explanou acerca da abordagem ecológica na aprendizagem de línguas e acerca da perspectiva holística de tradução cultural. Então, passou a um resumo da narrativa de um filme e solicitou aos alunos que assistissem ao filme sem legendas, em casa. A etapa seguinte foi a análise de cinco cenas da obra e a legendagem pedagógica na direção italiano-inglês. Na fase final, os estudantes compararam o produto de suas atividades, as legendas.

Lertola (2013) orienta que, antes de se iniciar tarefas com uso da legendagem, os aprendizes de LE devem tomar conhecimento das várias modalidades de TAV como também devem ter acesso às normas básicas de legendagem a serem seguidas. Dessa forma, a autora, em seu trabalho, adaptou para os participantes de sua pesquisa o Code of Good Subtitling 
Practice $^{23}$. Ela destaca que os aprendizes devem, antes de tudo, estar conscientes que a legendagem requer qualidade de tradução, ou seja, ao produzir um texto de tradução, deve-se respeitar elementos linguísticos e culturais do texto-fonte.

Nesse ponto, compreendemos a postura da autora, porém entendemos que a produção do texto de tradução vai muito além desses dois elementos sublinhados. Elementos de ordem pragmática, como o relevo dado aos indivíduos envolvidos no processo tradutório, devem receber a devida atenção para não incorrermos na produção de um texto alvo que se posicione servilmente a um texto-fonte ${ }^{24}$. Lertola (2013) destaca ainda que os estudantes de LE precisam estar atentos a aspectos como o espaço reservado às legendas, as quais não devem ultrapassar um total de 41 caracteres por linha, bem como à quebra de linha, ou segmentação de legendas, respeitando-se unidades semânticas e sintáticas.

Versari e Marins (2014) publicaram a implementação de um projeto intitulado "A legendagem como recurso pedagógico para a aprendizagem de LI no ensino médio”. Com uma produção didático-pedagógica dividida em 6 unidades, utilizaram um software de legendagem gratuito chamado Gnome subtitles. O ambiente de trabalho foi o laboratório de informática da escola.

A unidade 1 abordou aspectos técnicos da legendagem de uma forma geral e como ela é praticada no Brasil. Na unidade 2, falou-se sobre curiosidades a respeito da legendagem, sobre estratégias de leitura e sobre tradução para legendagem. Nesse ponto, os alunos compararam uma tradução profissional com uma amadora, disponível na web, e com as próprias propostas de tradução que eles fizeram. Segundo as autoras, isso facilitou a aprendizagem do módulo. $\mathrm{Na}$ unidade 3, foi trabalhado o manuseio do software Gnome Subtitles (VERSARI E MARINS, 2014).

Na unidade 4, explorou-se o gênero "filme". A professora-pesquisadora gravou um vídeo em inglês sobre o tema e postou no Youtube. Os alunos assistiram ao vídeo e como primeira prática com o Gnome Subtitles fizeram a legendagem dele em português (legendas intralinguais). A unidade 5 foi um trabalho com o gênero trailer em que os alunos, em trios, selecionaram um trailer de um filme de sua preferência, criaram legendas para ele e abordaram fatos histórico-culturais relacionados à obra. Enfatizou-se, nas aulas, a peculiaridade do trabalho do legendista, o qual deve ser bicultural e atender às normas exigidas pela atividade de tradução. A unidade 6 contemplou as animações Connect e The Key to my heart, em que,

\footnotetext{
${ }^{23}$ Cf. Carroll e Ivarsson (1998).

${ }^{24}$ Cf. Nord (2006); Even-Zohar (2004).
} 
previamente ao trabalho de legendagem, discutiu-se questões relacionadas a namoro e ao preconceito sofrido pelas loiras tanto no Brasil quanto fora do país (VERSARI E MARINS 2014).

Em Lertola (2012), encontramos, também, uma rotina pedagógica. Os participantes trabalharam na legendagem de um excerto de um filme italiano contemporâneo. Na fase de prétarefa ( $1^{\mathrm{a}} \mathrm{h} / \mathrm{a}$ do curso, o qual teve duração $4 \mathrm{~h} / \mathrm{a}$ distribuídas em quatro semanas), os participantes fizeram atividades que se resumiram em assistir ao vídeo duas vezes, inicialmente sem áudio, e em fazer inferências a fim de promover um debate sobre a interpretação do texto audiovisual. O restante do curso consistiu em assistir ao vídeo com transcrições das falas em italiano e em operar sua tradução na direção italiano-inglês, incorporando as legendas ao vídeo por meio de um software de legendagem.

Pode-se perceber que o investimento de tempo e de recursos para implementação de tarefas de legendagem não é pequeno. Assim, seguindo McLoughlin e Lertola (2014), entendemos que a aplicação dessas tarefas em sala de LE deve ser sistemática, a fim de aproveitarmos melhor o tempo inicial investido no treinamento com softwares de legendagem. Uma vez familiarizados com a tecnologia, os alunos certamente poderão aproveitar melhor os benefícios linguísticos advindos desse tipo de tarefa.

\section{Considerações finais}

Apesar do número ainda restrito de pesquisas nessa área (conseguimos selecionar somente 20 trabalhos), todos esses estudos demonstram um potencial promissor para o uso de tarefas de legendagem no ensino de LE. O modelo de ensino baseado em tarefas parece ser o mais adequado à implementação das rotinas pedagógicas, uma vez que na pré-tarefa pode-se fornecer informações sobre a TAV e mais especificamente sobre a legendagem.

O processo, de fato, figura como o componente mais relevante, pois gera oportunidades de interação entre professor-aluno e entre aluno-aluno, favorecendo a ampliação da zona de desenvolvimento proximal ${ }^{25}$. O tipo de input fornecido por meio do trabalho de TAV se coaduna à hipótese da compreensão ${ }^{26}$, já que os elementos da tarefa, como instrumentos de pesquisa e o texto multimodal, facilitam a compreensão do input. Em termos de produção

\footnotetext{
${ }^{25}$ Cf. Vigotsky (2007).

${ }^{26}$ Cf. Krashen (2009).
} 
linguística ${ }^{27}$, o trabalho de tradução, seja interlingual ou intralingual, favorece o desenvolvimento de habilidades linguístico-culturais, porque o cotejo do texto-fonte com o texto de tradução faz com os aprendizes reflitam de forma bastante crítica sobre a produção textual. Essa reflexão pode acontecer tanto de forma exteriorizada, verbalizada na interação em sala de aula, como por meio de mecanismos metalinguísticos como a fala privada e interior ${ }^{28}$.

A pós-tarefa, em atividades de legendagem de vídeos, é um momento oportuno para a discussão das propostas de tradução. A qualidade de feedback fornecida pelo professor de LE, durante e após a tarefa, é crucial para o desenvolvimento dos estudantes. Nesse ensejo, é aconselhável seguir premissas de scaffolding, nas quais o professor orienta os alunos nas resoluções de problemas, sem, contudo, fornecer respostas prontas.

Em última análise, neste estudo, a tarefa de legendagem traz consigo diversos benefícios ao ensino de LE. Ela põe os estudantes em uma posição ativa, fazendo com que sejam sujeitos do seu aprendizado; ela promove o desenvolvimento de um letramento digital, já que os alunos têm que manusear um software de legendagem e fazer pesquisas nos mais variados ambientes virtuais; ela desenvolve facilmente habilidades linguísticas e culturais, por ter como suporte textos ricos em informações verbais e não-verbais. Dessa forma, pode-se orientar tarefas que visem, também, ampliar o conhecimento intercultural dos alunos, fazendo com que eles percebam nuances como, por exemplo, os porquês de algumas culturas ocuparem posições centrais enquanto outras permanecem em posições periféricas, em determinados contextos de valoração estética ou científica.

\section{REFERÊNCIAS}

AL-DABBAGH, U. K. Teaching Subtitling at Jordanian Universities: An Untapped Territory. Journal of Language Teaching and Research. Amã, v. 8, n. 1, p. 16-25, 2017.

ARAÚJO, V. L. S. The educational use of subtitled films in EFL teaching. In: DÍAZ CINTAS, Jorge (Ed.). The Didactics of Audiovisual Translation. Amsterdam and Philadelphia: John Benjamins, 2008. p. 227-238.

BAÑOS, R.; SOKOLI, S. Learning foreign languages with ClipFlair: Using captioning and revoicing activities to increase students' motivation and engagement. In: K. BORTHWICK,

\footnotetext{
${ }^{27}$ Cf. Swain (1993).

${ }^{28}$ Cf. Vigotsky (2009); Figueiredo (2019).
} 
K.; CORRADINI, E.; DICKENS, A. (Ed.). 10 years of the LLAS elearning symposium:

Case studies in good practice. Dublin: Research-publishing.net, 2015. p. 203-213.

BESEGHI, M. Having fun in the classroom: subtitling activities. De Gruyter Mouton. Berlim, p. 395-407, 2013.

BIANCHI, F. Subtitling Science: An efficient task to learn content and language. Lingue Linguaggi. Salento, n. 15, p. 7-25, 2015.

BORGHETTI, C.; LERTOLA, J. Interlingual subtitling for intercultural language education: a case study. Routledge, Language and intercultural communication. Londres, v. 14, n. 4, p. 423-440, 2014.

BRAVO, M. C. C. Putting the Reader in the Picture: Screen Translation and Foreign Language Learning. 2008. 246 f. Tese (Doutorado em Tradução e Estudos Interculturais) Programa de Doutorado em Tradução e Estudos Interculturais. Universidade Rovira i Virgili, Espanha, 2008.

CARROLL, Mary; IVARSSON, Jan. Code of Good Subtitling Practice. Approved at the meeting of the European Association for Studies in Screen Translation in Berlin 17.10.1998. Disponível em: < http://www.transedit.se/code.htm>. Acesso em: 5 de set. de 2016.

CINTAS, Jorge (Ed.). The Didactics of Audiovisual Translation. Amsterdam and Philadelphia: John Benjamins, 2008. p. 227-238.

CAIMI, Annamaria. Subtitling: Language Learner's Needs vs. Audiovisual. In: DÍAZ CINTAS, Jorge; ANDERMAN, Gunilla (Ed.). Audiovisual Translation: Language Transfer on Screen. Londres: CPI Antony Rowe, Chippenham and Eastbourne, 2009. p. 240-251.

CHAGAS, R. M. F. M. CINEMA EM SALA: os filmes como recursos didáticos para a aula de leitura em LE. 2005. 241 f. Dissertação (Mestrado em Linguística) - Instituto de Letras e Linguística, Universidade Federal de Uberlândia, Uberlândia, 2005.

CIRUGEDA, I. L.; RUIZ, R. S. Subtitling as a Didactic Tool: A Teacher Training Experience. Porta Linguarum. Espanha, n. 20, p. 45-62, 2013.

DANAN, Martine. Captioning and Subtitling: Undervalued Language Learning Strategies. Meta: Translators' Journal, [S.l.], v. 49, n. 1, p. 67-77, 2004. Disponível em: < https://www.erudit.org/revue/meta/2004/v49/n1/009021ar.pdf >. Acesso em: 5 de set. De 2016.

. Reversed Subtitling and Dual Coding Theory: New Directions for Foreign Language Instruction. (1992). Disponível em: < https://www.researchgate.net/publication/227967890_Reversed_Subtitling_and_Dual_Coding _Theory_New_Directions_for_Foreign_Language_Instruction

>. Acesso em: 5 de set. de 2016.

DÍAZ CINTAS, Jorge (Ed.). The Didactics of Audiovisual Translation. Amsterdam e Filadélfia: John Benjamins, 2008. 263 p. 
DÍAZ CINTAS, Jorge; CRUZ, M. F. Using subtitled video materials for foreign language instruction. In: DÍAZ CINTAS, Jorge (Ed.). The Didactics of Audiovisual Translation. Amsterdam e Filadélfia: John Benjamins, 2008. p. 201-214.

EVEN-ZOHAR, Itamar. The Position of Translated Literature within the Literary Polysystem. In: VENUTI, Lawrence (Ed.). The Translation Studies Reader. Nova Iorque: Routledge: 2004. p. 192-197.

FAZILATFAR, A. M.; GHORBANI, S.; SAMAVARCHI, L. The effect of standard and reversed subtitling versus no subtitling mode on 12 vocabulary learning. The Journal of Teaching Language Skills (JTLS), [S.l.], 3(1), p. 43-64, 2011. Disponível em: < http://jtls.shirazu.ac.ir/article_393_7a6bf9ac256c5a814a3eea8cbdc69747.pdf>. Acesso em: 5 de set. de 2016.

FIGUEIREDO, F. J. Q. Vygotsky: a interação no ensino/aprendizagem de línguas. $1^{\mathrm{a}}$ ed. São Paulo: Parábola, 2019. 125 p.

FREIRE, P. Pedagogia da Autonomia: saberes necessários à prática educativa. Rio de Janeiro: Paz e Terra, 2018. 143 p.

GOMES, F. W. B. Filmes legendados e ensino de línguas adicionais: um breve panorama sobre as pesquisas no Brasil. Horizontes de Linguística Aplicada, Brasília, v. 15, n. 1, p. 4169, 2016. Disponível em: <

http://periodicos.unb.br/index.php/horizontesla/article/view/12244/13987>. Acesso em: 4 de set. de 2016.

GOMES, F. W. B. O Uso de Filmes Legendados como Ferramenta para o

Desenvolvimento da Proficiência Oral de Aprendizes de Língua Inglesa. 2006. 132 f.

Dissertação (Mestrado em Linguística Aplicada) - Programa de Pós-Graduação em

Linguística Aplicada, Universidade Estadual do Ceará, Fortaleza, 2006.

HSU et al. Effects of Video Caption Modes on English Listening Comprehension and Vocabulary Acquisition Using Handheld Devices. Educational Technology \& Society, [S.l.], 16 (1), p. 403-414, 2013. Disponível em: < http://www.ifets.info/journals/16_1/35.pdf >. Acesso em: 5 de set. de 2016.

KRASHEN, Stephen. Principles and Practice in Second Language Acquisition.

Disponível em: 〈http://www.sdkrashen.com/content/books/principles_and_practice.pdf>. Acesso em: 21 de maio de 2016. 202 p. First internet edition July 2009.

LAVIOSA, S. Developing Translingual and Transcultural Competence through Pedagogic Subtitling. Linguaculture. Romênia, n. 1, p. 72-88, 2015.

LERTOLA, J. Subtitling New Media: Audiovisual Translation and Second Language Vocabulary Acquisition. 2013. 243 f. Tese (Doutorado em Estudos Italianos). Universidade Nacional de Irlanda, Galway, 2013. 
LERTOLA, J. The effect of the subtitling task on vocabulary learning. In: PYM, A.; ORREGO-CARMONA, D. (Ed.). Translation Research Projects 4. Tarragona: Intercultural Studies Group, 2012. p. 61-70.

MATIELO, Rafael; COLLET, Thais; D'ELY, R. C. S. F. The effects of interlingual and intralingual subtitles on vocabulary learning by Brazilian EFL learners: An exploratory study. Revista Intercâmbio. São Paulo, v. XXVII, p. 83-99, 2013. Disponível em: <http://revistas.pucsp.br/index.php/intercambio/article/viewFile/17691/13189>. Acesso em: 31 maio 2016.

MATIELO, Rafael; D’ELY, R. C. S. F.; BARETTA, Luciane. The effects of interlingual and intralingual subtitles in second language learning/aquisition: a state-of-the-art review. Trab. Ling. Aplic. Campinas, n. (54.1), p. 161-182, 2015. Disponível em: <http://www.scielo.br/pdf/tla/v54n1/0103-1813-tla-54-01-00161.pdf >. Acesso em: de 31 maio de 2016.

MARZBAN, A.; ZAMANIAN, M. The Impact of the Subtitling Task on Vocabulary Learning of Iranian EFL Learners. Journal of Applied Linguistics and Language Research. Iran, v. 2, p. 1-9, 2015.

MCLOUGHLIN, L. I.; LERTOLA, J. Audiovisual translation in second language acquisition: Integrating subtitling in the foreign-language curriculum. Routledge, The Interpreter and Translator Trainer. Londres, v. 8, n. 1, p. 70-83, 2014.

NEVES, Josélia. Language awareness through training in subtitling. In: ORERO, Pilar (Ed.). Topics in audiovisual translation. Amsterdam: John Benjamins, 2004. p. 127-140.

NORD, C. Loyalty and Fidelity in Specialized Translation. Confluências - Revista de Tradução Científica e Técnica, [S.1.], n. 4, 2006. p. 29-41. 2016. Disponível em: <http://web.letras.up.pt/egalvao/TTCIP_Nord loyatly and fidelity.pdf $>$. Acesso em: 5 de set. de 2018.

OLIVEIRA FILHO, Luiz. Utilização da legendagem intralingüística no desenvolvimento da proficiência oral em língua francesa. 2008. 132 f. Dissertação (Mestrado em Linguística Aplicada) - Pos-Graduacao em Linguistica Aplicada, Universidade Estadual do Ceará, Fortaleza, 2008.

PAVESI, Maria; PEREGO, Elisa. Tailor-made interlingual subtitling as a means to enhance second language acquisition. In: DÍAZ CINTAS, Jorge (Ed.). The Didactics of Audiovisual Translation. Amsterdam e Filadélfia: John Benjamins, 2008. p. 215-226.

SOKOLI, S. Learning via Subtitling (LvS): A tool for the creation of foreign language learning activities based on film subtitling. MuTra - Audiovisual Translation Scenarios: Conference Proceedings. Copenhague, p. 1-8, 2006.

SWAIN, M. The Output Hypothesis: Just Speaking and Writing aren't enough. 1993. Disponível em: < https://2010-soph-writingnccu.wikispaces.com/file/view/05+Swain+(1993)+The+Output+Hypothesis.pdf $>$. Acesso em: 8 de jul. de 2018. 
TALAVÁN, N.; RODRÍGUEZ-ARANCÓN, P. The Interpreter and Translator Trainer. Routledge. Londres, v. 8, n. 1, p. 84-101, 2014.

VERSARI, S. M. S.; MARINS, L. C. A legendagem como recurso pedagógico para a aprendizagem de língua inglesa no ensino médio. Cadernos PDE, Os desafios da escola pública paranaense na perspectiva do professor PDE. Paraná, v. 1, 2014. Não paginado.

VIGOTSKY, L. S. A construção do pensamento e da linguagem. $2^{\text {a }}$ ed. São Paulo: Editora Martins Fontes, 2009. 496 p.

. A formação social da mente. $7^{\mathrm{a}}$ ed. São Paulo: Martins Fontes, 2007. 182 p.

WILLIAMS, H.; THORNE, D. The value of teletext subtitling as medium for language learning. Pergamon. Oxford, p. 217-228, 2000.

ZANÓN, N. T. Subtitling as a task and subtitles as support: pedagogical applications. In: DÍAZ CINTAS, J.; MATAMALA, A.; NEVES, J. (Eds). New Insights into Audiovisual Translation and Media. Acessibility. Amsterdan, Nova Iorque: Rodopi, 2010. p. 285-299.

. Using the Technique of Subtitling to Improve Business Communicative Skills.

Revista de Lenguas para Fines Específicos. Las Palmas de Gran Canária, n. 11, p. 313-346, 2006b.

. Using subtitles to enhance foreign language learning. Porta Linguarum. Granada, n. 6, p. 41-52, 2006a.

Recebido em 03/02/2020. Aceito em 09/06/2020. 